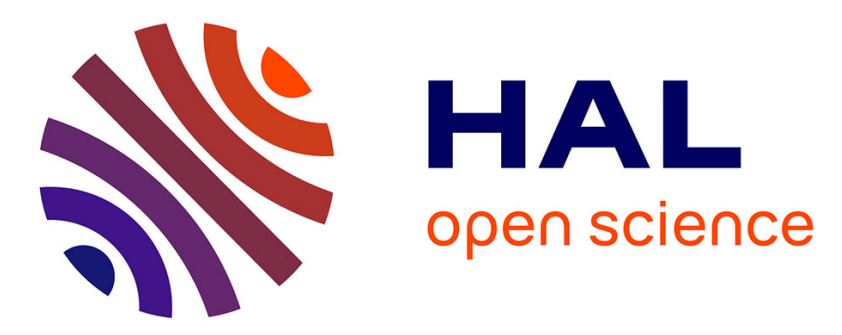

\title{
Coordination-Driven Construction of Porphyrin Nanoribbons at a Highly Oriented Pyrolytic Graphite (HOPG)/Liquid Interface
}

Mary-Ambre Carvalho, Hervé Dekkiche, Mayumi Nagasaki, Yoshihiro Kikkawa, Romain Ruppert

\section{To cite this version:}

Mary-Ambre Carvalho, Hervé Dekkiche, Mayumi Nagasaki, Yoshihiro Kikkawa, Romain Ruppert. Coordination-Driven Construction of Porphyrin Nanoribbons at a Highly Oriented Pyrolytic Graphite (HOPG)/Liquid Interface. Journal of the American Chemical Society, 2019, 141 (26), pp.10137-10141. $10.1021 /$ jacs.9b02145 . hal-02175658

\section{HAL Id: hal-02175658 \\ https://hal.science/hal-02175658}

Submitted on 5 Jul 2019

HAL is a multi-disciplinary open access archive for the deposit and dissemination of scientific research documents, whether they are published or not. The documents may come from teaching and research institutions in France or abroad, or from public or private research centers.
L'archive ouverte pluridisciplinaire HAL, est destinée au dépôt et à la diffusion de documents scientifiques de niveau recherche, publiés ou non, émanant des établissements d'enseignement et de recherche français ou étrangers, des laboratoires publics ou privés. 


\title{
$\mathrm{J}$

\section{Coordination-Driven Construction of Porphyrin Nanoribbons at a 2Highly Oriented Pyrolytic Graphite (HOPG)/Liquid Interface}

\author{
3 Mary-Ambre Carvalho, ${ }^{\dagger}$ Hervé Dekkiche, ${ }^{\dagger}$ Mayumi Nagasaki, ${ }^{\ddagger}$ Yoshihiro Kikkawa,*,+(0) \\ 4 and Romain Ruppert* ${ }^{*} \dagger$ \\ $5{ }^{\dagger}$ Institut de Chimie, UMR 7177 du CNRS, Université de Strasbourg, 4 rue Blaise Pascal, 67000 Strasbourg, France \\ $6{ }^{ \pm}$National Institute of Advanced Industrial Science and Technology (AIST), 1-1-1 Higashi, Tsukuba, Ibaraki 305-8565, Japan
}

\begin{abstract}
Nanostructures were built at the solid/ liquid interface by self-assembly and/or coordination bonds. Metalloporphyrins bearing two external coordination sites and long alkyl chains allowed the self-assembly of the compounds on highly oriented pyrolitic graphite. After addition of a metal ion, long transition-metal linked porphyrin nanoribbons were obtained and visualized by scanning tunneling microscopy. In these porphyrin ribbons electronic delocalization is possible through the $\mathrm{d}$ orbitals of the connecting metal ions.
\end{abstract}

${ }_{18} \mathrm{R}$ uilding well-ordered supramolecular architectures from ${ }_{19}$ functional subunits might be potentially useful for 20 applications in (opto)electronics, magnetism, energy harvest21 ing, or smart coatings. The bottom-up synthesis is an 22 interesting method to obtain such ordered nanomaterials by 23 using noncovalent interactions. This strategy was discussed 24 two decades ago by leading scientists. ${ }^{1,2}$ In particular, using 25 these approaches to prepare nanowires or nanotubes will be of 26 importance for future technological applications. Porphyrins 27 are good candidates for the construction of nanostructures in 28 many fields of applications due to their interesting optoelec29 tronical properties. The synthesis of long conjugated porphyrin 30 wires using covalent linkages was started more than two 31 decades ago. Triple bonds as connecting functions were the 32 most widely used because strong electronic or magnetic 33 interactions occur between the subunits. ${ }^{3,4}$ At the beginning of 34 this century, the Osuka group synthesized very long conjugated 35 porphyrin tapes, in which the individual porphyrins are fused 36 and linked by three covalent bonds. ${ }^{5}$ However, the syntheses of 37 all these molecules often remain a challenge and therefore 38 preclude possible practical applications.

39 It was possible to assemble porphyrins bearing external 40 coordination sites with metal ions in solution. ${ }^{6}$ Strong 41 electronic interactions were demonstrated between the 42 individual subunits in porphyrin dimers (see 1 in Chart 1 , 43 top) by using enamino(thio)ketones as ligands for the 44 connecting ions. These external coordination sites can also 45 be described as noninnocent ligands, thus allowing electronic 46 delocalization over the entire molecule through the $d$ orbitals 47 of the linking metal ion, and this was corroborated by DFT 48 studies. ${ }^{7}$ Larger molecules were obtained by using porphyrins 49 bearing two external coordination sites (examples of such
Chart 1. Porphyrin Dimers 1 Linked by Metal Ions (Top); Two Porphyrin Monomers Used in This Study: 2 with a Center of Symmetry and 3 with a Plane of Symmetry (Bottom)

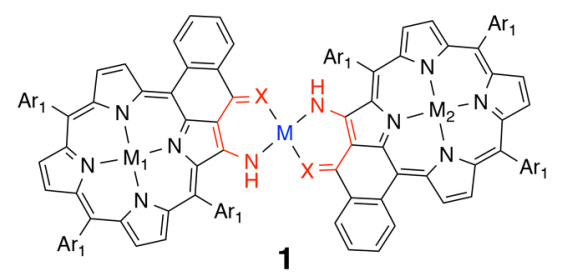

$\mathrm{Ar}_{1}=\mathrm{Ph}$ or $3,5-{ }^{\mathrm{t}} \mathrm{Bu} 2-\mathrm{Ph}$ $\mathrm{X}=\mathrm{O}$ or $\mathrm{S}$

$\mathrm{M}=\mathrm{Ni}, \mathrm{Cu}, \mathrm{Pd}, \mathrm{Pt}$ $M_{1}, M_{2}=H_{2}, Z n, N i, C u$

2a or $3 \mathbf{a}: \mathrm{Ar}_{2}=3,5-{ }^{-} \mathrm{Bu}_{2} \mathrm{Ph}$ 2b or $\mathbf{3 b}: \mathrm{Ar}_{2}=4-\mathrm{C}_{18} \mathrm{H}_{37} \mathrm{Ph}$ 3c : $\mathrm{Ar}_{2}=4-\mathrm{C}_{12} \mathrm{H}_{25} \mathrm{Ph}$

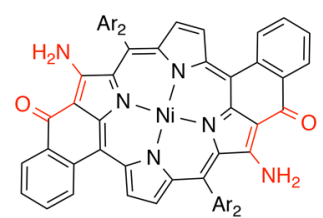

2

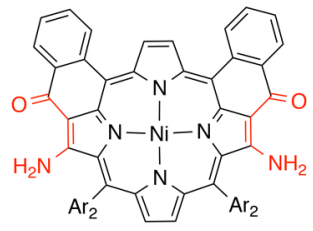

3 molecules used in these studies are shown in Chart 1, 2a and 50 3a bottom). ${ }^{8,9}$

However, the selective preparation of molecules containing more than three or four porphyrins by this coordination 53 chemistry linkage approach proved to be as challenging as the 54 covalent bond formation approach.

On-surface synthesis to obtain new functional molecules has 56 attracted intense attention over the past decade. Steering the 57 reaction outcome and improving the chemo- and regioselec- 58 tivity during these processes remain a real challenge because it 59 is difficult to modify the reaction parameters under UHV 60 conditions. $^{10}$ Most previous studies were conducted on 61 metallic surfaces at relatively high temperatures to obtain 62 potential functional nanostructures containing conjugated 63 molecules, polyaromatics, or even oligoporphyrins. ${ }^{11-15}$ The 64 on-surface approach, but under much milder reaction 65 conditions, in solvents and using noncovalent bond forming 66 reactions as assembling tools at a liquid/HOPG interface was 67 therefore considered by different groups. ${ }^{16-19}$ The self- 68 assembled structures have been revealed by using scanning 69 tunneling microscopy ${ }^{20,21}$ (STM) at the solid/liquid inter- 70 face. $^{22-24}$ Well-organized structures can be generated this way, 71

Received: February 25, 2019

Published: June 11, 2019 
72 but interactions between the individual units are generally 73 rather small. ${ }^{25-34}$

74 Porphyrin monomers or presynthesized dimers such as $\mathbf{1}$ 75 bearing long alkoxy chains self-assembled at the liquid/highly 76 oriented pyrolytic graphite (HOPG) surface. 9 To prepare 77 higher oligoporphyrins linked by metal ions, porphyrins 78 bearing two external coordination sites in addition to long 79 meso-alkylphenyl groups are needed. The Ar meso substituents 80 used in the present studies were phenyl groups bearing $\mathrm{C}_{18} \mathrm{H}_{37}$ 81 alkyl chains in the para positions $\left(\mathrm{Ph}-\mathrm{C}_{18} \mathrm{H}_{37}\right)$. To obtain 82 linear porphyrin ribbons, two series of symmetrical porphyrin 832 and 3 (with a center or a plane of symmetry) were used for 84 the self-assembly process. Porphyrins such as $\mathbf{2} \mathbf{b}$ and $\mathbf{3 b}$ were 85 obtained by following procedures used earlier for the 86 preparation of similar porphyrins (see Supporting Information 87 (SI) for experimental details).

88 Before starting the on-surface studies, we had noticed in the 89 X-ray structure of compound $3 c$ that linear tapes with 90 molecules held together by hydrogen bonds were present 91 (see Figure 1). In the solid state, the molecules of 3c (bearing

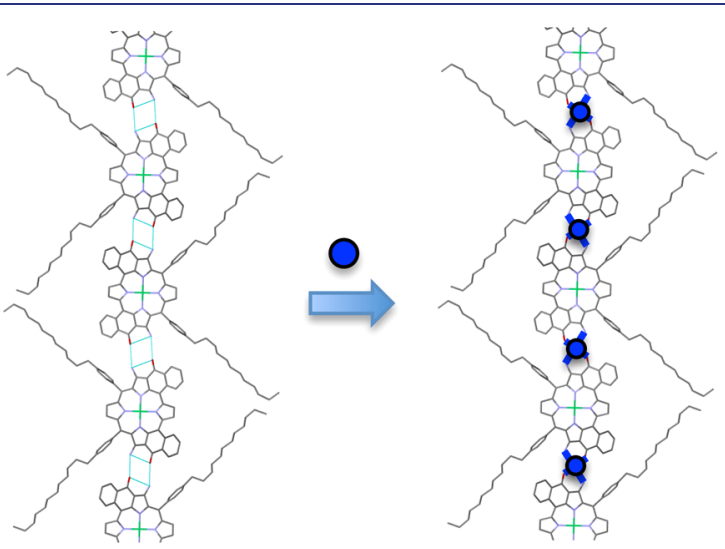

Figure 1. X-ray structure of compound $3 c\left(\mathrm{Ar}=\mathrm{PhC}_{12} \mathrm{H}_{25}\right)$. Hydrogen bonds between the individual porphyrins are schematically drawn in light blue, $d(\mathrm{Ni}-\mathrm{Ni})=14.339 \AA$ (left). Right: expected formation of nickel(II)-connected porphyrin nanoribbons.

92 two $\mathrm{Ph}-\mathrm{C}_{12} \mathrm{H}_{25}$ meso groups) are arranged in such a way that 93 the two external coordination sites were already preorganized 94 to build square planar metal complexes if divalent metal ions 95 are added. $^{35}$ Similar arrangements of porphyrin $\mathbf{3 b}$ at the 96 solid/liquid interface were therefore expected, and the 97 construction of linear ribbons with porphyrins linked by 98 metal ions could be envisaged directly at the interface 99 (according to the schematic representation shown in Figure 1001 at the right).

101 Drop casting a phenyloctane solution of porphyrin $\mathbf{3 b}$ onto a 102 HOPG surface gave a well-organized arrangement of the 103 porphyrins at the solid/liquid interface. However, the addi104 tional interactions of the alkyl chains with the hexagonal 105 HOPG surface led to a different arrangement of the molecules 106 than in the solid-state structure. Two porphyrins were 107 assembled in centro-symmetric pairs held together by 108 hydrogen bonds, and all pairs were separated by a space (see 109 Figure $2 a$ and $2 b$ ).

110 Apart from this observation, the expected alternating 111 arrangement of molecules was present at the interface and 112 the porphyrins were aligned in rows separated by spaces filled 113 by the alkyl chains that interact with HOPG. The distance $\left(\mathrm{L}_{1}\right.$ 114 in Figure $2 \mathrm{~b}$ ) between the porphyrin rows was $2.8 \pm 0.1 \mathrm{~nm}$.
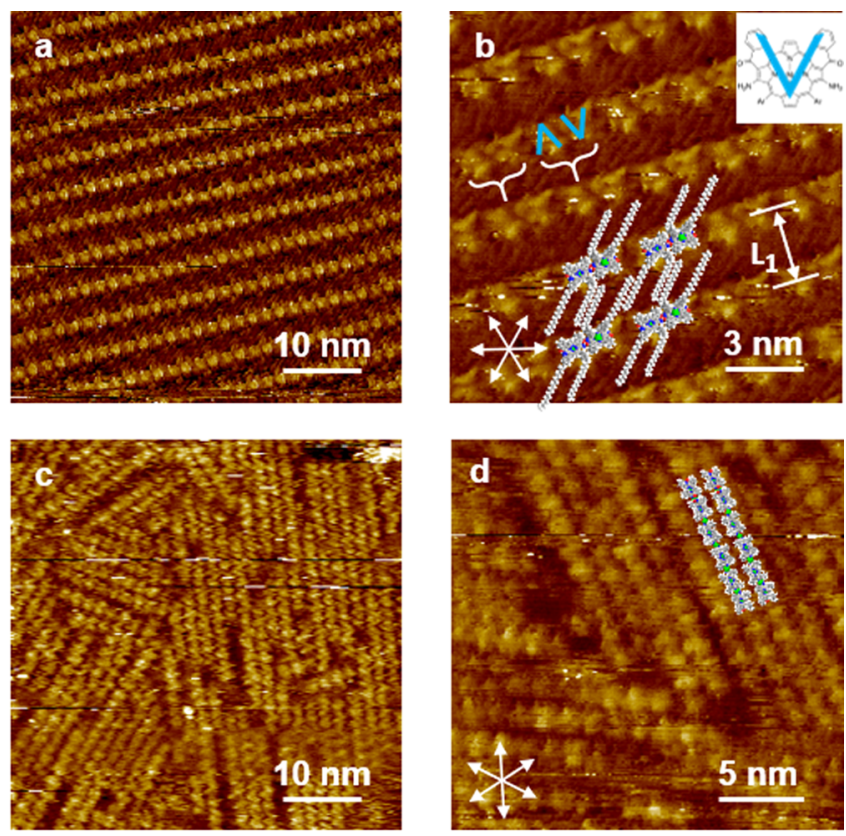

Figure 2. STM height images of compound $3 \mathbf{b}\left(\mathrm{Ar}=\mathrm{PhC}_{18} \mathrm{H}_{37}\right)$ before (a, b) and after the addition of nickel(II) (c, d) at the HOPG/ phenyloctane interface $(c=1 \mathrm{mM})$. Pairs are highlighted with brackets in (b). Proposed molecular models were superimposed on the STM images in (b) and (d). In (d), the C18 alkyl chains were replaced by $\mathrm{CH}_{3}$ groups. Arrows indicate the HOPG lattice directions. Tunneling conditions: (a) $I=1.1 \mathrm{pA}, V=-103 \mathrm{mV}$, (b) $I=1.2 \mathrm{pA}, V$ $=-164 \mathrm{mV}$, (c) $I=1.6 \mathrm{pA}, V=-989 \mathrm{mV}$, (d) $I=1.4 \mathrm{pA}, V=-818$ $\mathrm{mV}$.

The C18 alkyl chains were sandwiched between the porphyrin 115 rows with an angle of ca. $40^{\circ}$. Varying the concentration of the 116 porphyrin $3 \mathbf{b}$ down to $0.1 \mathrm{mM}$ gave similar arrangements at 117 the interface (see SI). It should be emphasized at this point 118 that these very ruffled porphyrins ${ }^{36}$ are functionalized with 119 only two $\mathrm{C}_{18} \mathrm{H}_{37}$ alkyl chains, thus necessitating the use of 120 rather high concentrations (from 0.05 to $1 \mathrm{mM}$ ). Addition of 121 an equimolar amount of nickel(II) $\left(\mathrm{Ni}(\mathrm{acac})_{2}\right.$ in $\mathrm{CH}_{2} \mathrm{Cl}_{2} / 122$ phenyloctane) drastically changed the arrangement of the 123 molecules at the interface. We noticed in the early stage of this 124 study that these arrangements also evolved over time after the 125 addition of the metal salt and that the equilibrium was reached 126 after approximately $1 \mathrm{~h}$. Figure $2 \mathrm{c}$ and $2 \mathrm{~d}$ show the 127 arrangements of porphyrin $\mathbf{3 b} \mathbf{b}$ h after addition of nickel(II). 128 The formation of long linear ribbons (maximum length ca. 30129 $\mathrm{nm}$ ) of porphyrins linked by nickel(II) can be visualized in 130 Figure 2d. Note that similar observations of linear ribbons were 131 available for both a premixed solution of $\mathrm{Ni}(\mathrm{II})$ and $\mathbf{3 b}$ as well 132 as after in situ addition of $\mathrm{Ni}(\mathrm{II})$ to the deposited solution of 133 $\mathbf{3 b}$ on the HOPG surface. These results suggest that oligomers 134 observed for the in situ experiment might be preferentially 135 formed in solution and then compete with monomers 136 adsorbed at the interface.

At the $1 \mathrm{mM}$ concentration, most of the individual ribbons 138 were not separated by alkyl chain areas and were densely 139 packed at the interface (Figure 3a), as shown by the measured $140 \mathrm{f} 3$ distance between the neighboring ribbons $\left(\mathrm{L}_{2}=1.6 \pm 0.1 \mathrm{~nm} ; 141\right.$ Figure $3 \mathrm{~b})$. The interactions of the long aromatic systems with 142 HOPG were large enough to keep the linear arrays on HOPG, 143 and the alkyl chains were oriented toward the solution. 144 Lowering stepwise the concentration from $1 \mathrm{mM}$ to $0.05 \mathrm{mM} 145$ 

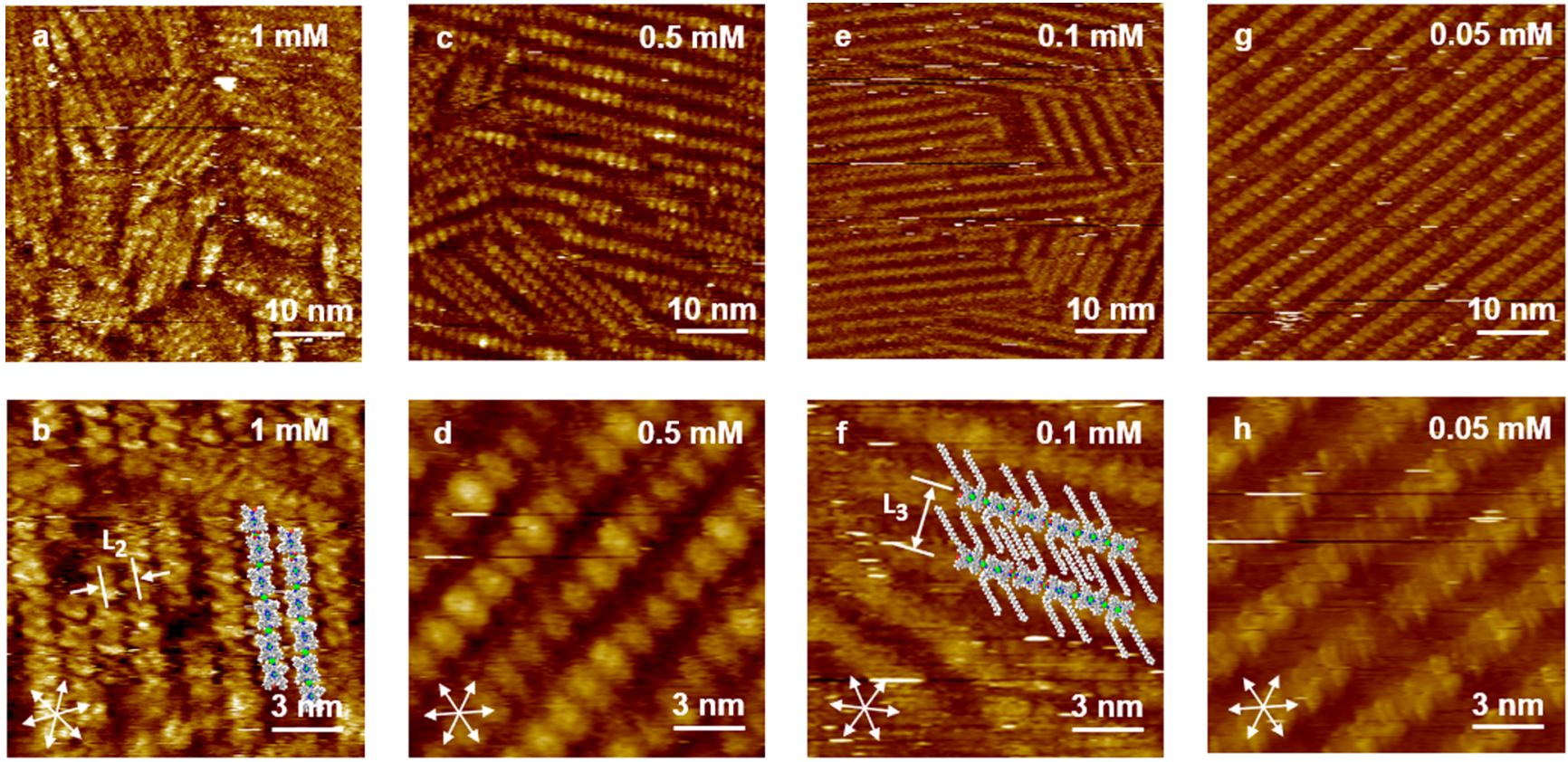

Figure 3. STM height images of porphyrin $\mathbf{3 b}$ at different concentrations after addition of 1 equiv of nickel(II). Assuming a similar orientation of the alkyl chains (as in Figure 2b), a molecular model of linear ribbons with sparse packing was superimposed on the STM image in (f). Concentrations of the solution are indicated on each STM image. Tunneling conditions: (a) $I=1.0 \mathrm{pA}, V=-752 \mathrm{mV},(\mathrm{b}) I=2.0 \mathrm{pA}, V=-948$ $\mathrm{mV}$, (c) $I=1.9 \mathrm{pA}, V=-740 \mathrm{mV}$, (d) $I=3.8 \mathrm{pA}, V=-823 \mathrm{mV}$, (e) $I=2.4 \mathrm{pA}, V=-942 \mathrm{mV}$, (f) $I=3.1 \mathrm{pA}, V=-744 \mathrm{mV},(\mathrm{g}) I=1.0 \mathrm{pA}, V=$ $-1000 \mathrm{mV}$, (h) $I=5.0 \mathrm{pA}, V=-1000 \mathrm{mV}$.

146 gave images with more sparsely packed areas (see Figure 3). At 147 a concentration of $0.1 \mathrm{mM}$, well-separated ribbons were 148 formed almost exclusively. The distance $\mathrm{L}_{3}$ between them was $1492.7 \pm 0.1 \mathrm{~nm}$, which was almost identical to the value of $\mathrm{L}_{1}$ 150 found for $\mathbf{3 b}$ without $\mathrm{Ni}(\mathrm{II})$. This result suggests that the 151 nanoribbons are adsorbed on the HOPG with the assistance of 152 alkyl chains, which are packed between the porphyrin rows.

153 It is not possible to compare studies in solution with studies 154 at the HOPG/liquid interface. However, in order to have an 155 idea of the electronic structure of the linear arrays at the 156 surface, solution experiments were performed at concen157 trations close to those used earlier to generate the nanoribbons 158 at the interface. An equimolar amount of $\mathrm{Ni}(\mathrm{acac})_{2}$ was added 159 to a toluene solution of porphyrin $3 \mathbf{b}$ in a thin quartz cell. The 160 electronic spectrum was recorded as a function of time. The 161 results of the first measurements are depicted in Figure 4. As 162 the complexation reaction progressed in solution, a bath163 ochromic shift of all absorption bands was observed. The

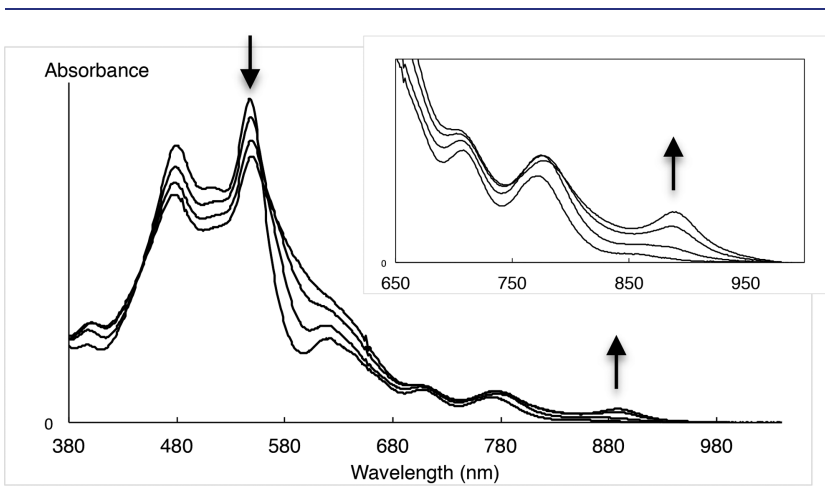

Figure 4. Electronic spectra of monomer $3 \mathbf{b}$ as a function of time after addition of 1 equiv of $\mathrm{Ni}(\mathrm{acac})_{2}$ in toluene $(t=0,5,20$, and $60 \mathrm{~min})$. reaction could not be monitored to completion because the 164 metal ion linked oligoporphyrins formed after addition of 165 $\mathrm{Ni}(\text { acac })_{2}$ were also adsorbed on the quartz faces of the 166 cuvette, giving rise to light-diffusion phenomena. However, the 167 evolution of the first four spectra clearly indicated that strong 168 interactions between porphyrin subunits linked by nickel(II) 169 ions were present in the oligoporphyrins. A flattening and 170 broadening of the bands in the Soret area (from 450 to 600171 $\mathrm{nm}$ ) and a bathochromic shift of the $Q$ bands to wavelengths 172 higher than $900 \mathrm{~nm}$ are the signature of strong electronic 173 interactions between the aromatic $\pi$-electrons of each 174 individual porphyrin induced by the participation of the $d 175$ orbitals of the linking metal ions.

To demonstrate that this approach was not limited to 177 porphyrin $\mathbf{3 b}$, centro-symmetric porphyrin monomer $\mathbf{2 b}(\mathrm{Ar}=178$ $\left.\mathrm{PhC}_{18} \mathrm{H}_{37}\right)$ was also prepared. Once more, the self-assembly of 179 the individual molecules was studied at the HOPG/liquid 180 interface. The STM images obtained for millimolar phenyl- 181 octane solutions of $\mathbf{2} \mathbf{b}$ were not as well resolved as for 182 porphyrin $3 \mathrm{~b}$ (see Figure 5a). However, to see if the $183 \mathrm{fs}$ oligoporphyrins could be constructed and visualized at the 184 interface, the same procedure described earlier for $\mathbf{3 b}$ was 185 followed. The STM images in Figure 5b clearly showed that, 186 again, long linear nanoribbons of porphyrins were present at 187 the interface. As observed before for $\mathbf{3 b}$, large areas of the 188 surface were occupied by alkyl chains for monomer $\mathbf{2 b}$, but 189 upon addition of $\mathrm{Ni}(\mathrm{acac})_{2}$, the porphyrin nanoribbons were 190 again densely packed on the surface.

In conclusion, we have demonstrated that long linear 192 porphyrin nanoribbons can be constructed at the HOPG/ 193 liquid interface by using a combination of weak interactions 194 (hydrogen bonds, van der Waals interactions with the surface 195 and/or between alkyl chains) and also stronger coordination 196 linkages. By combining these two factors, the best of both 197 

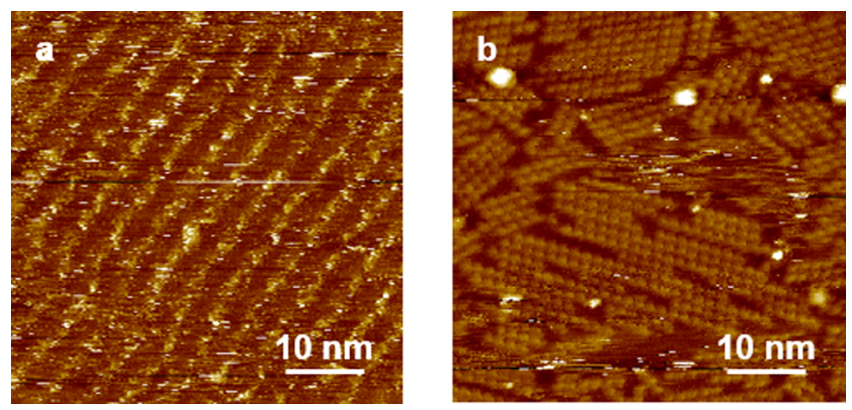

Figure 5. STM height images of porphyrin $\mathbf{2 b}(1 \mathrm{mM}$ phenyloctane solution): (a) before and (b) after addition of an equimolar amount of $\mathrm{Ni}(\mathrm{acac})_{2}$. Tunneling conditions: (a) $I=2.0 \mathrm{pA}, V=-515 \mathrm{mV}$, (b) $I=1.3 \mathrm{pA}, V=-405 \mathrm{mV}$.

198 worlds was reached, i.e. the rapid reversibility of the weak 199 interactions followed by stable coordination linkages. The 200 coordination linkages (divalent metal ions + enaminoketone 201 chelating ligands) used in this study also present the advantage 202 of adding electronic communication between the subunits in 203 addition to their connecting role.

\section{ASSOCIATED CONTENT}

205 S Supporting Information

206 The Supporting Information is available free of charge on the 207 ACS Publications website at DOI: 10.1021/jacs.9b02145.

208 Synthetic procedures, characterization (NMR, mass and 209 electronic spectra) of all new compounds, X-ray data of 210 compound $\mathbf{3 b}$, additional STM images (PDF)

211 Crystallographic data for $\mathbf{3 b}$ (CIF)

\section{AUTHOR INFORMATION}

213 Corresponding Authors

214 *ruppert@unistra.fr

$215 *$ y.kikkawa@aist.go.jp

216 ORCID $\odot$

217 Yoshihiro Kikkawa: 0000-0003-3635-4751

218 Romain Ruppert: 0000-0002-1513-1949

219 Notes

220 The authors declare no competing financial interest.

\section{ACKNOWLEDGMENTS}

222 Continuous financial support from the CNRS and the 223 University of Strasbourg is acknowledged. H.D. thanks the 224 French Ministry of Research for a PhD fellowship. M.A.C. 225 thanks the FRC-Labex CSC for her PhD fellowship (ANR-10226 LABX-0026 CSC). Y.K. thanks the JSPS KAKENHI 227 (17K05851).

\section{REFERENCES}

229 (1) Lehn, J.-M. Toward Self-Organization and Complex Matter. 230 Science 2002, 295, 2400-2403.

231 (2) Whitesides, G. M.; Grzybowski, B. Self-Assembly at All Scales. 232 Science 2002, 295, 2418-2421.

233 (3) Anderson, H. L. Conjugated Porphyrin Ladders. Inorg. Chem. 234 1994, 33, 972-981. Lin, V. S.-Y.; DiMagno, S. G.; Therien, M. J. 235 Highly Conjugated, Acetylenyl Bridged Porphyrins: New Models for 236 Light-Harvesting Antenna Systems. Science 1994, 264, 1105-1111.

237 (4) Wang, R.; Brugh, A. M.; Rawson, J.; Therien, M. J.; Forbes, M. 238 D. E. Alkyne-Bridged Multi[Copper(II) Porphyrin] Structures: 239 Nuances of Orbital Symmetry in Long-Range, Through-Bond
Mediated, Isotropic Spin Exchange Interactions. J. Am. Chem. Soc. 240 2017, 139, 9759-9762.

(5) Tsuda, A.; Osuka, A. Fully Conjugated Porphyrin Tapes with 242 Electronic Absorption Bands That Reach into Infrared. Science 2001, 243 293, 79-82.

244

(6) Richeter, S.; Jeandon, C.; Gisselbrecht, J.-P.; Ruppert, R.; Callot, 245 H. J. Syntheses and Optical and Electrochemical Properties of 246 Porphyrin Dimers Linked by Metal Ions. J. Am. Chem. Soc. 2002, 124, 247 6168-6179.

248

(7) Dekkiche, H.; Buisson, A.; Langlois, A.; Karsenti, P.-L.; 249 Ruhlmann, L.; Harvey, P. D.; Ruppert, R. Ultrafast Singlet Energy 250 Transfer in Porphyrin Dyads. Inorg. Chem. 2016, 55, 10329-10336. 251

(8) Richeter, S.; Jeandon, C.; Ruppert, R.; Callot, H. J. A Modular 252 Approach to Porphyrin Oligomers Using Metal Ions as Connectors. 253 Chem. Commun. 2002, 266-267.

254

(9) Carvalho, M.-A.; Dekkiche, H.; Karmazin, L.; Sanchez, F.; 255 Vincent, B.; Kanesato, M.; Kikkawa, Y.; Ruppert, R. Synthesis and 256 Study at a Solid/Liquid Interface of Porphyrin Dimers Linked by 257 Metal Ions. Inorg. Chem. 2017, 56, 15081-15090. 258

(10) Two recent examples of porphine or porphyrine coupling: 259 Bischoff, F.; He, Y.; Riss, A.; Seufert, K.; Auwärter, W.; Barth, J. V. 260 Exploration of Interfacial Porphine Coupling Schemes and Hybrid 261 Systems by Bond-Resolved Scanning Probe Microscopy. Angew. 262 Chem., Int. Ed. 2018, 57, 16030-16035. Bengasi, G.; Baba, K.; Frache, 263 G.; Desport, J.; Gratia, P.; Heinze, K.; Boscher, N. D. Boscher, N. D. 264 Conductive Fused Porphyrin Tapes on Sensitive Substrates by a 265 Chemical Vapor Deposition Approach. Angew. Chem., Int. Ed. 2019, 266 58, 2103-2108.

267

(11) Matena, M.; Riehm, T.; Stöhr, M.; Jung, T. A.; Gade, L. 268 Transforming Surface Coordination Polymers into Covalent Surface 269 Polymers: Linked Polycondensed Aromatics through Oligomerization 270 of N-Heterocyclic Carbene Intermediates. Angew. Chem., Int. Ed. 271 2008, 47, 2414-2417.

(12) Wang, T.; Huang, J.; Lv, H.; Fan, Q.; Feng, L.; Tao, Z.; Ju, H.; 273 Wu, X.; Tait, S. L.; Zhu, J. Kinetic Strategies for the Formation of 274 Graphyne Nanowires via Sonogashira Coupling on $\mathrm{Ag}(111)$. J. Am. 275 Chem. Soc. 2018, 140, 13421-13428.

(13) Moreno, C.; Paradinas, M.; Vilas-Varela, M.; Panighel, M.; 277 Ceballos, G.; Pena, D.; Mugarza, A. On-Surface Synthesis of 278 Superlattice Arrays of Ultra-Long Graphene Nanoribbons. Chem. 279 Commun. 2018, 54, 9402-9405.

280

(14) Shu, C.-H.; Xie, Y.-L.; Wang, A.; Shi, K.-J.; Zhang, W.-F.; Li, 281 D.-Y.; Liu, P.-N. On-Surface Reactions of Aryl Chloride and 282 Porphyrin Macrocycles via Merging two Reactive Sites into a Single 283 Precursor. Chem. Commun. 2018, 54, 12626-12629. 284

(15) Haq, S.; Hanke, F.; Dyer, M. S.; Persson, M.; Iavicoli, P.; 285 Amabilino, D. B.; Raval, R. Clean Coupling of Unfunctionalized 286 Porphyrins at Surfaces to Give Highly Oriented Organometallic 287 Oligomers. J. Am. Chem. Soc. 2011, 133, 12031-12039. 288

(16) Elemans, J. A. A. W.; Lei, S.; De Feyter, S. Molecular and 289 Supramolecular Networks on Surfaces: From Two-Dimensional 290 Crystal Engineering to Reactivity. Angew. Chem., Int. Ed. 2009, 48, 291 7298-7332.

(17) Gomar-Nadal, E.; Puigmarti-Luis, J.; Amabilino, D. B. Assembly 293 of Functional Molecular Nanostructures on Surfaces. Chem. Soc. Rev. 294 2008, 37, 490-504.

295

(18) Mali, K. S.; Pearce, N.; De Feyter, S.; Champness, N. R. 296 Frontiers of Supramolecular Chemistry at Solid Surfaces. Chem. Soc. 297 Rev. 2017, 46, 2520-2542.

298

(19) Cui, D.; MacLeod, J. M.; Rosei, F. Probing Functional Self- 299 Assembled Molecular Architectures with Solution/Solid Scanning 300 Tunneling Microscopy. Chem. Commun. 2018, 54, 10527-10539. 301

(20) Binnig, G.; Rohrer, H.; Gerber, C.; Weibel, E. Surface Studies 302 by Scanning Tunneling Microscopy. Phys. Rev. Lett. 1982, 49, 57-61. 303

(21) Stöhr, M. In Supramolecular Chemistry - Scanning Tunneling 304 Microscopy (STM); Gale, P. A., Steed, J. W., Eds.; John Wiley \& Sons, 305 Ltd.: Chichester, 2012; pp 659-668. 
307 (22) De Feyter, S.; De Schryver, F. C. Self-Assembly at the Liquid/ 308 Solid Interface: STM Reveals. J. Phys. Chem. B 2005, 109, 42903094302.

310 (23) Otsuki, J. STM Studies on Porphyrins. Coord. Chem. Rev. 2010, $311254,2311-2341$.

312 (24) Geng, Y.-F.; Li, P.; Li, J.-Z.; Zhang, X.-M.; Zeng, Q.-D.; Wang, 313 C. STM Probing the Supramolecular Coordination Chemistry on 314 Solid Surface: Structure, Dynamic, and Reactivity. Coord. Chem. Rev. 315 2017, 337, 145-177.

316 (25) Marschall, M.; Reichert, J.; Weber-Bargioni, A.; Seufert, K.; 317 Auwärter, W.; Klyatskaya, S.; Zoppellaro, G.; Ruben, M.; Barth, J. V. 318 Random Two-Dimensional String Networks Based on Divergent 319 Coordination Assembly. Nat. Chem. 2010, 2, 131-137.

320 (26) Heim, D.; Ecija, D.; Seufert, K.; Auwärter, W.; Aurisicchio, C.; 321 Fabbro, C.; Bonifazi, D.; Barth, J. V. Self-Assembly of Flexible One322 Dimensional Coordination Polymers on Metal Surfaces. J. Am. Chem. 323 Soc. 2010, 132, 6783-6790.

324 (27) Koepf, M.; Wytko, J. A.; Bucher, J.-P.; Weiss, J. Surface-Tuned 325 Assembly of Porphyrin Coordination Oligomers. J. Am. Chem. Soc. 326 2008, 130, 9994-10001.

327 (28) El Garah, M.; Marets, N.; Mauro, M.; Aliprandi, A.; Bonacchi, 328 S.; De Cola, L.; Ciesielski, A.; Bulach, V.; Hosseini, M. W.; Samori, P. 329 Nanopatterning of Surfaces with Monometallic and Heterobimetallic 330 1D Coordination Polymers: A Molecular Tectonics Approach at the 331 Solid/Liquid Interface. J. Am. Chem. Soc. 2015, 137, 8450-8459.

332 (29) Velpula, G.; Li, M.; Hu, Y.; Zagranyarski, Y.; Pisula, W.; 333 Müllen, K.; Mali, K. S.; De Feyter, S. Hydrogen-Bonded Donor334 Acceptor Arrays at the Solution-Graphite Interface. Chem. - Eur. J. 335 2018, 24, 12071-12077.

336 (30) Sun, X.; Fan, L.; Zhou, X.; Tian, W. Q.; Guo, Z.; Li, Z.; Li, X.; 337 Lei, S. Surface Confined Synthesis of Porphyrin Containing Two338 Dimensional Polymers: The Effect of Rigidity and Preferential 339 Adsorption of Building Blocks. Chem. Commun. 2015, 51, 58643405867.

341 (31) Sakamoto, R.; Takada, K.; Pal, T.; Maeda, H.; Kambe, T.; 342 Nishihara, H. Coordination Nanosheets (CONASHs): Strategies, 343 Structures and Functions. Chem. Commun. 2017, 53, 5781-5801.

344 (32) Cai, L.; Sun, Q.; Bao, M.; Ma, H.; Yuan, C.; Xu, W. 345 Competition between Hudrogen Bonds and Coordination Bonds 346 Steered by the Surface Molecular Coverage. ACS Nano 2017, 11, 347 3727-3732.

348 (33) Sosa-Vargas, L.; Kim, E.; Attias, A.-J. Beyond "Decorative" 2D 349 Supramolecular Self-Assembly: Strategies towards Functional Surfaces 350 for Nanotechnology. Mater. Horiz. 2017, 4, 570-583.

351 (34) Amabilino, D. B. in Supramolecular Chemistry at Surfaces. 352 Monographs in Supramolecular Chemistry; Royal Society of Chemistry, 3532016.

354 (35) CCDC deposit number: 1893245.

355 (36) Shelnutt, J. A.; Song, X.-Z.; Ma, J.-G.; Jia, S.-L.; Jentzen, W.; 356 Medforth, C. J. Nonplanar Porphyrins and their Significance in 357 Proteins. Chem. Soc. Rev. 1998, 27, 31-41. 